\title{
Concordant preferences for actual height and facial cues to height
}

\author{
D.E. Re*, D.I. Perrett \\ School of Psychology, University of St. Andrews, St. Andrews, Scotland KY16 9JP, United Kingdom
}

\section{A R T I C L E I N F O}

\section{Article history:}

Received 8 May 2012

Received in revised form 28 June 2012

Accepted 2 July 2012

Available online 28 July 2012

\section{Keywords:}

Mate choice

Face perception

Physical stature

Body size

Attraction

\begin{abstract}
A B S T R A C T
Physical height has a well-documented effect on human mate preferences. In general, both sexes prefer opposite-sex romantic relationships in which the man is taller than the woman, while individual preferences for height are affected by a person's own height. Research in human mate choice has demonstrated that attraction to facial characteristics, such as facial adiposity, may reflect preferences for body characteristics. Here, we tested preferences for facial cues to height. In general, increasing apparent height in men's faces and slightly decreasing apparent height in women's faces maximizes perceived attractiveness. Individual preferences for facial cues to height were predicted by self-reported preferences for actual height. Furthermore, women's own height predicted opposite-sex preferences for facial cues to apparent height, though this finding did not extend to male participants. These findings validate the use of facial cues to height and demonstrate a further component of facial attractiveness that reflects preferences for body characteristics.
\end{abstract}

(c) 2012 Elsevier Ltd. All rights reserved.

\section{Introduction}

Physical height has a well-documented impact on human social interaction. Taller people obtain greater career success in the business world (Judge \& Cable, 2004) and are more often promoted to positions of authority (Gawley, Perks, \& Curtis, 2009). On average, taller men obtain a higher education (Magnusson, Rasmussen, \& Gyllensten, 2006) and taller men and women earn a higher average income than their shorter counterparts (Meyer \& Selmer, 1999; Rashad, 2008; Steckel, 1983). Taller men are more likely to ascend to positions of political leadership (McCann, 2001; Murray \& Schmitz, 2011; Sorokowski, 2010), and successful political candidates are judged to be taller after winning an election than beforehand (Higham \& Carment, 1992). The link between height and career success may be explained by personality correlates of height. Taller members of both sexes have higher reported self-esteem (Judge \& Cable, 2004), and behave in a more dominant manner (Melamed, 1992), and tall men report more frequent acts of aggression (Archer \& Thanzami, 2007). Consistent with these personality traits, taller people are perceived as stronger, smarter and more dominant (Cawley, Joyner, \& Sobal, 2006; Montepare, 1995). The association between height and conflict success is even present in preverbal infants, who show more surprise when taller vertical

\footnotetext{
* Corresponding author. Address: School of Psychology, University of St. Andrews, St. Mary's College, St. Andrews, Fife, Scotland KY16 9JP, United Kingdom. Tel.: +44 (0) 1334463044 .

E-mail addresses: dr296@st-andrews.ac.uk (D.E. Re), dp@st-andrews.ac.uk (D.I. Perrett)
}

lines back away from shorter lines in computer simulations (Thomsen, Frankenhuis, Ingold-Smith, \& Carey, 2011).

Just as height influences social status, it also has an impact on mate choice (Courtiol, Raymond, Godelle, \& Ferdy, 2010). Both men and women prefer romantic relationships in which the man is taller than the woman (Courtiol et al., 2010; Higgins, Zheng, Liu, \& Sun, 2002; Jackson \& Ervin, 1992; Pawlowski, 2003; Salska et al., 2008). Women prefer taller men (Shepperd \& Strathman, 1989 ) in general, though perhaps not extremely tall men (Courtiol et al., 2010; Hensley, 1994). Taller men receive more interest from women in personal advertisements (Pawlowski \& Koziel, 2002) and are rated as more desirable in speed-dating events (Kurzban \& Weeden, 2005). Men's preferences for women's heights are less clear, with various studies reporting male preferences for short (Shepperd \& Strathman, 1989), average height (Swami et al., 2008), or taller than average (Courtiol et al., 2010) women. Previous research has demonstrated assortative preferences for height, with height preferences being influenced by a person's own height (Fink, Neave, Brewer, \& Pawlowski, 2007; McManus \& Mascie-Taylor, 1984; Pawlowski, 2003; Salska et al., 2008; Swami et al., 2008), and taller women and shorter men are more tolerant of dating partners of their own height (i.e. - prefer a lower "sexual dimorphism in stature"; Pawlowski, 2003). Further research has demonstrated that women have stronger preferences for tall men during the fertile phase of their menstrual cycle (Pawlowski \& Jasienska, 2005), and that women's height preferences in men are positively predicted by conformity to views on traditional gender roles and positively correlate with personality traits such as self-esteem and extraversion (Swami et al., 2008). Consistent with reported height preferences, there is some evidence that taller men 
(Mueller \& Mazur, 2001; Pawlowski, Dunbar, \& Lipowicz, 2000), and short (Devi, Kumari, \& Srikumari, 1985) or average height women (Mueller, 1979; Nettle, 2002; Vetta, 1975) have greater reproductive success than people of other heights, though these effects are not replicated in all studies. See Sear (2010) and Stulp, Pollet, Verhulst, and Buunk (2012) for a full review of studies on height and reproductive success.

Human mate preferences are also greatly influenced by facial appearance. Facial attractiveness is dependent on several face parameters, including masculinity, symmetry, averageness and skin color and texture (Perrett, 2010; Rhodes, 2006; Thornhill \& Gangestad, 1999). Recent research has uncovered elements of facial attractiveness related to body characteristics. Male facial attractiveness has been found to positively correlate with body attractiveness (Fink, Taschner, Neave, Hugill, \& Dane, 2010), and grip strength (Fink, Neave, \& Seydel, 2007). Facial adiposity correlates with actual and perceived body mass index (BMI) (Coetzee, Chen, Perrett, \& Stephen, 2010; Coetzee, Perrett, \& Stephen, 2009), and altering facial adiposity in isolation affects facial attractiveness (Coetzee, Re, Perrett, Tiddeman, \& Xiao, 2011; Re et al., 2011). Such findings indicate that some components of facial attractiveness may reflect preferences for body characteristics.

Craniofacial research indicates that stature may be estimated from skull shape (Chiba \& Terazawa, 1998; Pelin, Zagyapan, Yazici, \& Kurkcuoglu, 2010; Rao et al., 2009), and face growth occurs coincidentally with body growth (Akgul \& Toygar, 2002; Enlow \& Hans, 1996; Ramanathan \& Chellappa, 2006), with taller men having longer faces and narrower jaws (Windhager, Schaefer, \& Fink, 2011). While height affects the preferred vertical location of features within a face (i.e. - taller people prefer faces with large foreheads and small chins, simulating the view of a face as seen from above; Geldart, 2008), to the authors' knowledge no studies have reported how face cues to body height influence attractiveness. Thornhill and Grammer (1999) found correlations between independent ratings of attractiveness in women's bodies and faces, suggesting the two domains act as a single ornament of quality, though the correlations were relatively low (face and frontal view of body, $r=.30$; face and back view of body, $r=.33$ ). Conversely, Peters, Rhodes, and Simmons (2007) found that face and body attractiveness did not interact in judgments of overall attractiveness, and Hönekopp, Rudolph, Beier, Liebert, and Müller (2007) found men's physical fitness correlates with body attractiveness, but not face attractiveness. These results indicate that faces and bodies have separate cues to attractiveness. Other studies have demonstrated that the face has a relatively greater impact than the body in judgments of overall attractiveness (Currie \& Little, 2009; Mueser, Grau, Sussman, \& Rosen, 1984; Peters et al., 2007), though this has not been replicated in all studies (Alicke, Smith, \& Klotz, 1986). Together, these studies indicate that face and body cues have independent effects on overall attractiveness. The effect of cues to height in the face should therefore be analysed independently of actual body height.

Here, we assessed whether preferences for facial cues to height reflected explicit height preferences. Furthermore, we examined whether preferences for facial cues to height are assortative based on own height, similar to the assortative preferences in body height reported elsewhere (Salska et al., 2008; Swami et al., 2008). Based on previous research on actual height preferences (Courtiol et al., 2010; Jackson \& Ervin, 1992; Pawlowski, 2003; Salska et al., 2008; Shepperd \& Strathman, 1989), we predict women will prefer faces of men who appear to be taller than average, and men will prefer faces of women who appear to be short to average height. We expect preferences for height cues in the face to reflect self-reported preferences for actual height. Finally, we predict preferences for facial cues to perceived height will correlate with evaluators' own height.

\section{Methods}

\subsection{Face stimuli}

We presented participants with Caucasian face images of 47 men (mean age $=25.25$ years, $\mathrm{SD}=4.64$ years, mean body mass in$\operatorname{dex}(B M I)=24.10 \mathrm{~kg} / \mathrm{m}^{2}, \mathrm{SD}=3.52 \mathrm{~kg} / \mathrm{m}^{2}, 4$ with partial beard $)$ and 83 women (mean age $=23.04$ years, $S D=3.81$ years, mean $\mathrm{BMI}=20.05 \mathrm{~kg} / \mathrm{m}^{2}, \mathrm{SD}=4.12 \mathrm{~kg} / \mathrm{m}^{2}$ ) that were obtained from a commercially available database of face images (available at www.3d.sk.com).All photographed individuals had their hair pulled back and were photographed under constant lighting and camera set-up. Face images were standardized for inter-pupillary distance. All faces were delineated with 189 points with custom face-processing software (Tiddeman, Burt, \& Perrett, 2001). Men's heights ranged from $168 \mathrm{~cm}$ to $192 \mathrm{~cm}$ (mean $=179.72 \mathrm{~cm}, \mathrm{SD}=6.43 \mathrm{~cm}$ ), and women's heights ranged from $156 \mathrm{~cm}$ to $184 \mathrm{~cm}$ (mean $=167.58 \mathrm{~cm}, \mathrm{SD}=6.33 \mathrm{~cm}$ ). Twenty-two participants $(11$ men, 11 women) were asked to "please rate how tall you think this person is in either feet and inches or cm" and were given eight evenly spaced height divisions from $152 \mathrm{~cm}$ to $203 \mathrm{~cm}\left(5^{\prime} 0^{\prime \prime}-\right.$ $\left.6^{\prime} 8^{\prime \prime}\right)$.The average apparent height for women's faces was $167.52 \mathrm{~cm}(\mathrm{SD}=3.08 \mathrm{~cm})$, while the average apparent height for men's faces was $179.71 \mathrm{~cm}(\mathrm{SD}=3.03 \mathrm{~cm})$, and inter-rater reliability was high for height ratings of both men's and women's faces (both Cronbach's $\alpha \geqslant 0.94$ ).

Face composites were created for experimental testing. Face composites were created by averaging three male or female faces together (Rowland \& Perrett, 1995), and reflected the average height of the population. Using face composites reduces the likelihood of possible facial anomalies that may confound experimental testing. Five male and five female face composites were created for testing.

We averaged the faces of the 10 people who were perceived as shortest and the 10 people perceived as tallest within each sex (referred to as 'perceived height prototypes'). The short female prototype had an apparent height of $162.9 \mathrm{~cm}$, while the tall female prototype had an apparent height of $172.2 \mathrm{~cm}$. The short male prototype had an apparent height of $175.7 \mathrm{~cm}$, while the tall male prototype had an apparent height of $183.8 \mathrm{~cm}$.

Each composite was transformed to simulate changes in apparent height. We created face shape continua of 20 steps for each composite by applying $\pm 100 \%$ of the shape difference between the perceived height prototypes of the same sex (Rowland \& Perrett, 1995). This created face continua of 20 images spanning from $100 \%$ 'perceived short' shape to $100 \%$ 'perceived tall' shape in $10 \%$ increments for each composite (see Fig. 1 for an abbreviated example). A validation task was conducted to ensure our apparent height transforms did in fact alter perceived height. Twenty-two participants ( 16 women, 6 men) were presented with individual images of two male and two female composites transformed $\pm 50 \%$ in apparent height. Participants were asked to rate how tall each person was on a scale of 1 (extremely short) to 7 (extremely tall). Paired-samples t-tests revealed that the composites increased in apparent height were rated as taller than those decreased in apparent height for both women's and men's faces (both $t(21) \geqslant 5.07$, both $p<0.01)$.

\subsection{Procedure}

One hundred and forty-seven women and 61 men (mean age $=24.72, \mathrm{SD}=10.56,84.1 \%$ White European) completed the study online. Participants filled out a survey to report sex, age, height, and preferred height of partner. All height questions could be reported in either feet and inches or centimetres in a drop-down 


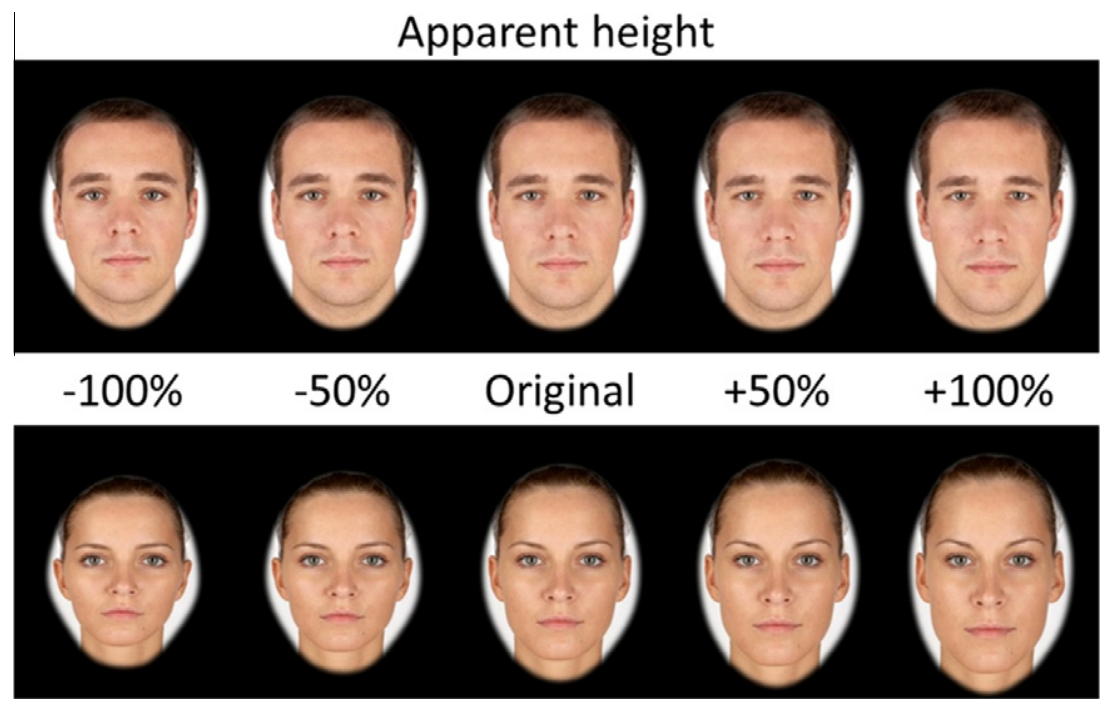

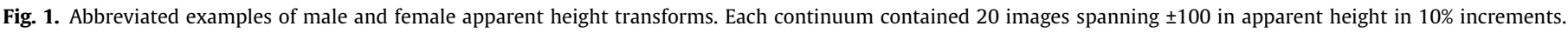

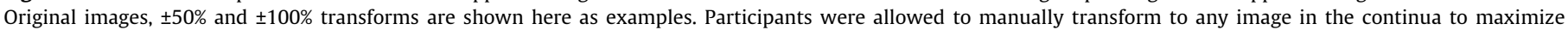
attractiveness.

menu of $1 \mathrm{~cm}$ increments from $136 \mathrm{~cm}\left(4^{\prime} 5^{\prime \prime}\right)$ to $212 \mathrm{~cm}\left(7^{\prime} 0^{\prime \prime}\right)$. Participants who reported an own height or preferred height of less than $147 \mathrm{~cm}\left(4^{\prime} 10^{\prime \prime}\right)$ were later excluded from analysis, as heights below this value are considered atypical (US National Library of Medicine, 2012) and may reflect inaccurate responses.

The 10 face transform continuums (five male and five female composites) were presented to the participants individually and in random order. A custom interactive program was created to allow participants to change face shape. Scrolling over the face would individually present consecutive images within a continuum, giving the effect that participants were "manually" changing the face shape. Participants were instructed to scroll over the face to manually transform the shape and asked to "Please change the face to make it most attractive". The starting degree of transformation of the face was randomized, and the scroll direction was randomized, (i.e. - scrolling to one side of the face would not always make the face appear taller). Such interactive tests have been successfully used in previous face research (Little, Jones, Penton-Voak, Burt, \& Perrett, 2002; Perrett et al., 1998).

\subsection{Analysis}

First, the average degree of transform required to maximize attractiveness in male and female faces was calculated, and we tested for differences between participant sexes. The apparent heights (in $\mathrm{cm}$ ) of the prototypes used in the perceived height transforms were known, thus we were able to convert the change in apparent height required to maximize attractiveness from degree of transform (in percentage) to theoretical centimetres. Next, two multivariate ANCOVAs were run to test for the effects of preferred height and own height on degree of face transform.

\section{Results}

On average, male participants slightly reduced apparent height in female faces by $1.89 \%(0.20 \mathrm{~cm} ; \mathrm{SD}=27.19 \%)$ to maximize attractiveness, while female participants slightly reduced apparent height in female faces by $6.09 \%(0.59 \mathrm{~cm}$; $\mathrm{SD}=26.50 \%)$. Male participants increased apparent height in male faces by $21.15 \%$ $(1.71 \mathrm{~cm} ; \mathrm{SD}=32.97 \%)$ to maximize attractiveness, while female participants increased apparent height in male faces by $15.32 \%$
$(1.24 \mathrm{~cm} ; \mathrm{SD}=32.38 \%)$. One way $t$-tests showed that, across all participants, women's faces were reduced in apparent height more than would be expected by chance $(t(207)=-2.63, p<0.01$, Cohen's $d=0.37)$, and men's faces were increased in apparent height more than would be expected by chance $(t(207)=7.54, p<0.01$, Cohen's $d=1.05$; Fig. 2). A one-way ANOVA found no differences between participant sex in the degree of transform for female $\left(F(1,207)=1.07, p=0.30, \eta_{p}^{2}<0.01\right)$ or male $(F(1,207)=1.38$, $\left.p=0.24, \eta_{p}^{2}=0.01\right)$ faces.

Multivariate ANCOVAs were run to test for the effect of participant's own height on apparent height preferences in male and female faces. For female participants, own height had an effect on apparent height preferences for male faces $(F(1,145)=4.37$, $p=0.04, \eta_{p}^{2}=0.03$; Fig. 3, top left), with taller women preferring greater apparent height in male faces. Women's own height did not have an effect on apparent height preferences for female faces $\left(F(1,145)=0.07, p=0.79, \eta_{p}^{2}<0.01\right)$. For male participants, own height did not have an effect on apparent height preferences for
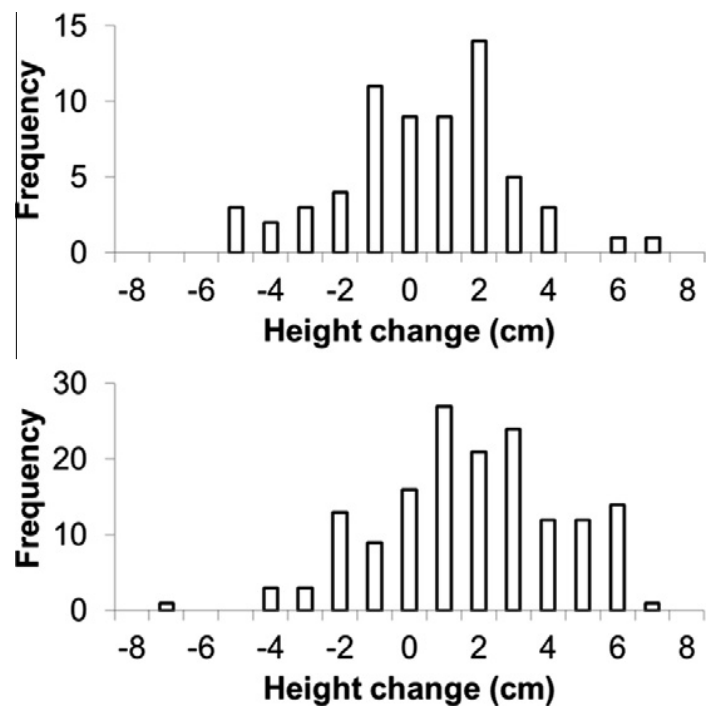

Fig. 2. Change in apparent height to maximize attractiveness. Histograms illustrating changes made in apparent height (in $\mathrm{cm}$ ) to maximize attractiveness for men viewing women's faces (top) and women viewing men's faces (bottom). 

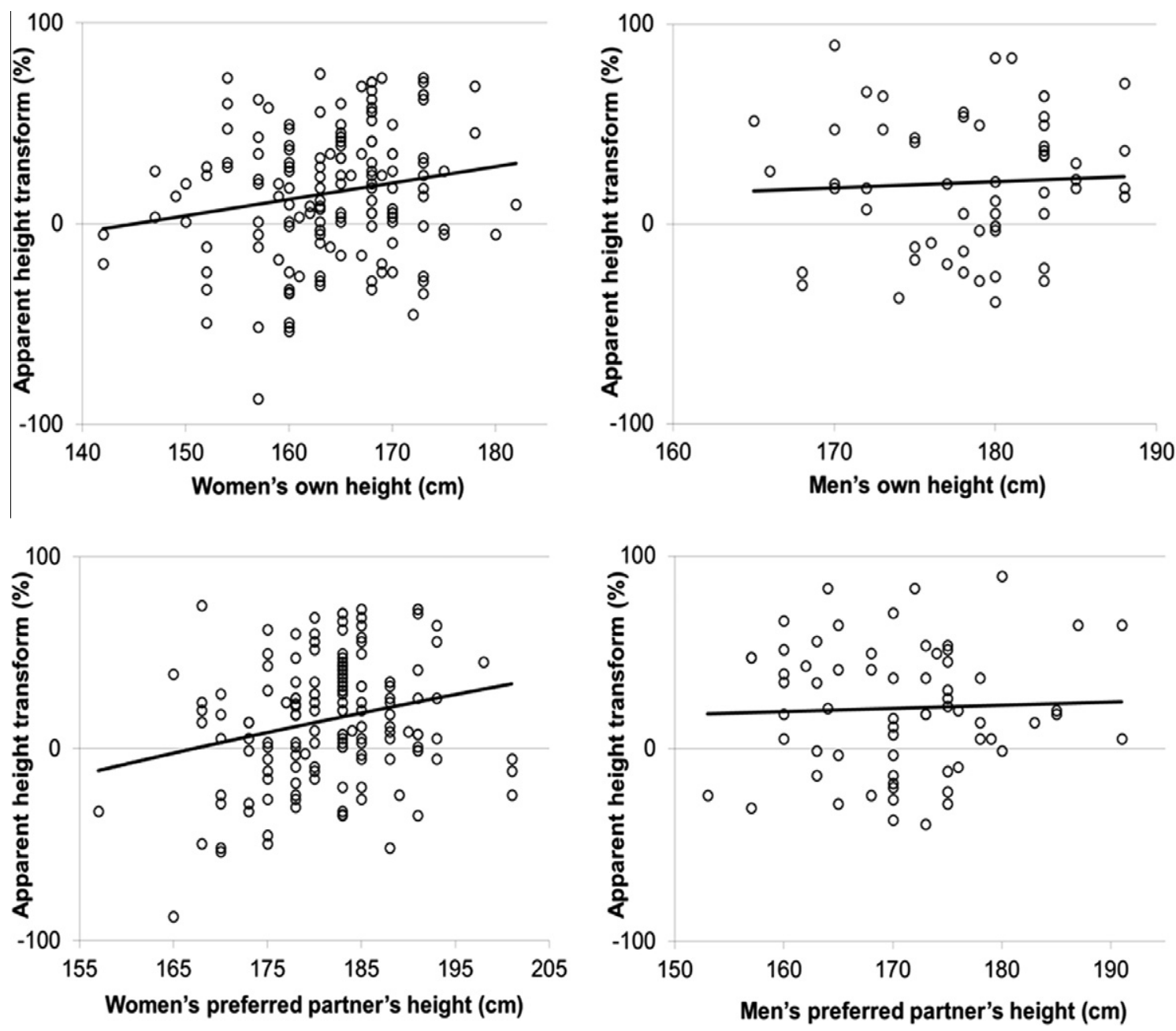

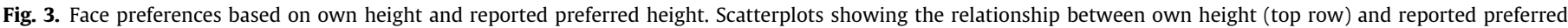

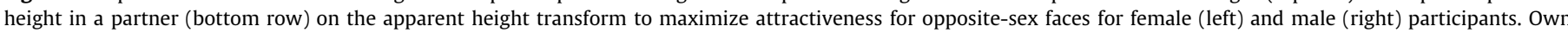

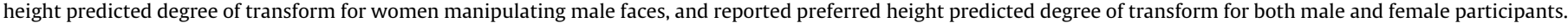

female $\left(F(1,59)=0.70, p=0.41, \eta_{p}^{2}=0.01\right.$; Fig. 3, top right $)$ or male $\left(F(1,59)<0.01, p=0.99, \eta_{p}^{2}<0.01\right)$ faces.

Multivariate ANCOVAs were run to test for the effects of reported preferred height in partners on degree of apparent height transform. For female participants, reported height preferences for partners predicted degree of apparent height transform in male faces $\left(F(1,145)=9.26, p<0.01, \eta_{p}^{2}=0.06\right.$; Fig. 3, bottom left $)$, but not female faces $\left(F(1,145)=0.44, p=0.51, \eta_{p}^{2}<0.01\right)$. For male participants, reported preferred height in partners predicted degree of apparent height transform in female faces $(F(1,61)=5.62$, $p=0.02, \eta_{p}^{2}=0.09$; Fig. 3 , bottom right), but not male faces $\left(F(1,61)=0.12, p=0.73, \eta_{p}^{2}<0.01\right)$.

\section{Discussion}

The current study finds that, from the average height of our sample, people prefer men's faces that are increased in apparent height and prefer women's faces that are slightly reduced in apparent height. These results mirror those found for preferences for body height (Higgins et al., 2002; Jackson \& Ervin, 1992; Pawlowski, 2003; Salska et al., 2008; Shepperd \& Strathman, 1989). Furthermore, the degree of transform used to maximize facial attractiveness was predicted by participants' reported preference for height in a partner, as well as by own height for female participants.
It should be noted that the average apparent height for men's faces in our sample was $179.71 \mathrm{~cm}$, while the average apparent height for women's faces was $167.52 \mathrm{~cm}$. We found that an average increase in apparent height of $1.37 \mathrm{~cm}$ for men's faces and a reduction of $0.47 \mathrm{~cm}$ for women's faces maximized attractiveness. Theoretically, this produces most attractive apparent heights of $181.08 \mathrm{~cm}$ and $167.05 \mathrm{~cm}$ for our population. While $181 \mathrm{~cm}$ is certainly taller than the average man in the vast majority of western countries, including the United States (www.cdc.gov) and the United Kingdom (http://www.ic.nhs.uk), $167 \mathrm{~cm}$ is also slightly taller than the average western female, though slightly shorter than the average female used in our sample. Thus, while relative trends in preferences for apparent height in faces (taller than average in men, average or slightly shorter than average in women) reflect body height preferences (Pawlowski, 2003; Salska et al., 2008; Shepperd \& Strathman, 1989), preferences for absolute height may be population specific.

Height preferences have been found to be assortative based on own height (Pawlowski, 2003; Salska et al., 2008; Swami et al., 2008). In the current experiments, women's own height predicted preferences for apparent height in men's faces, though men's own height did not predict preferences for apparent height in women's faces. Previous research has demonstrated that women place greater importance on height as a mate choice cue than men and that men are more tolerant of the idea of dating women taller than 
themselves, perhaps as a way to increase their potential mating pool (Salska et al., 2008). The current results indicate that this trend is upheld in preferences for face cues to apparent height. It should be noted that women increased apparent height in men's faces only by about $15 \%$ (out of a range of $\pm 100 \%$; or $1.24 \mathrm{~cm}$ out of a possible $8.08 \mathrm{~cm}$ ), which may mirror attenuated preferences for extremely tall height in men (Courtiol et al., 2010; Hensley, 1994).

Previous research has found that height preferences are influenced by individual differences. Women show a greater preference for tall men when in the ovulatory period of their menstrual cycle and when choosing a partner for a short-term relationship (Pawlowski \& Jasienska, 2005). Furthermore, preferences for greater sexual dimorphism in stature between two partners correlates with views conforming to typical sex roles, as well as personality attributes such as self-esteem and extraversion (Swami et al., 2008). Further research could test whether preferences for apparent height in the face are influenced by such individual differences. Given the alignment between the current results and those found for body height preferences, we predict any factor that affects preferences for body height will also affect preferences for facial cues to apparent height.

Body and face stimuli have independent effects on overall attractiveness judgments (Peters et al., 2007). Here, we find that preferences for face cues to apparent height match preferences reported in the body height literature. While the relative impact of face cues to height and actual body height on attractiveness are not known, several studies have found that faces have a greater effect on attractiveness judgments than bodies (Currie \& Little, 2009; Mueser et al., 1984; Peters et al., 2007). It is therefore likely that face cues to apparent height would impact perceived attractiveness even when actual body height is directly visible.

The current experiment indicates that preferences for facial cues to apparent height align with preferences for actual height reported elsewhere. Face preferences reflect preferences for body size in other domains, such as body weight (Coetzee et al., 2011). Our study finds that manipulating faces to alter perceived height can affect judgments of facial attractiveness.

\section{References}

Akgul, A. A., \& Toygar, T. U. (2002). Natural craniofacial changes in the third decade of life: A longitudinal study. American Journal of Orthodontics and Dentofacia Orthopedics, 122, 512-522.

Alicke, M. D., Smith, R. H., \& Klotz, M. L. (1986). Judgments of physical attractiveness - The role of faces and bodies. Personality and Social Psychology Bulletin, 12, 381-389.

Archer, J., \& Thanzami, V. (2007). The relation between physical aggression, size and strength, among a sample of young Indian men. Personality and Individual Differences, 43, 627-633.

Cawley, J., Joyner, K., \& Sobal, J. (2006). Size matters - The influence of adolescents weight and height on dating and sex. Rationality and Society, 18, 67-94.

Chiba, M., \& Terazawa, K. (1998). Estimation of stature from somatometry of skull. Forensic Science International, 97, 87-92.

Coetzee, V., Chen, J., Perrett, D. I., \& Stephen, I. D. (2010). Deciphering faces: Quantifiable visual cues to weight. Perception, 39, 51-61.

Coetzee, V., Perrett, D. I., \& Stephen, I. D. (2009). Facial adiposity: A cue to health? Perception, 38, 1700-1711.

Coetzee, V., Re, D., Perrett, D. I., Tiddeman, B. P., \& Xiao, D. K. (2011). Judging the health and attractiveness of female faces: Is the most attractive level of facial adiposity also considered the healthiest? Body Image, 8, 190-193.

Courtiol, A., Raymond, M., Godelle, B., \& Ferdy, J. B. (2010). Mate choice and human stature: Homogamy as a unified framework for understanding mating preferences. Evolution, 64, 2189-2203.

Currie, T. E., \& Little, A. C. (2009). The relative importance of the face and body in judgments of human physical attractiveness. Evolution and Human Behavior, 30 409-416.

Devi, M. R., Kumari, J. R., \& Srikumari, C. R. (1985). Fertility and mortality differences in relation to maternal body size. Annals of Human Biology, 12, 479-484.

Enlow, D. H., \& Hans, M. G. (1996). Essentials of facial growth. London: W.B. Saunders Company.

Fink, B., Neave, N., Brewer, G., \& Pawlowski, B. (2007). Variable preferences for sexual dimorphism in stature (SDS): Further evidence for an adjustment in relation to own height. Personality and Individual Differences, 43, 2249-2257.

Fink, B., Neave, N., \& Seydel, H. (2007). Male facial appearance signals physical strength to women. American Journal of Human Biology, 19, 82-87.
Fink, B., Taschner, K., Neave, N., Hugill, N., \& Dane, L. (2010). Male faces and bodies: Evidence of a condition-dependent ornament of quality. Personality and Individual Differences, 49, 436-440.

Gawley, T., Perks, T., \& Curtis, J. (2009). Height, gender, and authority status at work: Analyses for a national sample of Canadian workers. Sex Roles, 60, 208-222.

Geldart, S. (2008). Tall and good-looking? The relationship between raters' height and perceptions of attractiveness. Journal of Individual Differences, 29, 148-156.

Hensley, W. E. (1994). Height as a basis for interpersonal attraction. Adolescence, 29. 469-474.

Higgins, L. T., Zheng, M., Liu, Y., \& Sun, C. H. (2002). Attitudes to marriage and sexual behaviors: A survey of gender and culture differences in China and United Kingdom. Sex Roles, 46, 75-89.

Higham, P. A., \& Carment, D. W. (1992). The rise and fall of politicians - The judged heights of Broadbent, Mulroney and Turner before and after the 1988 Canadian federal election. Canadian Journal of Behavioural Science-Revue Canadienne Des Sciences Du Comportement, 24, 404-409.

Hönekopp, J., Rudolph, U., Beier, L., Liebert, A., \& Müller, C. (2007). Physical attractiveness of face and body as indicators of physical fitness in men. Evolution and Human Behavior, 28, 106-111.

Jackson, L. A., \& Ervin, K. S. (1992). Height stereotypes of women and men The liabilities of shortness for both sexes. Journal of Social Psychology, 132, 433-445.

Judge, T. A., \& Cable, D. M. (2004). The effect of physical height on workplace success and income: Preliminary test of a theoretical model. Journal of Applied Psychology, 89, 428-441.

Kurzban, R., \& Weeden, J. (2005). HurryDate: Mate preferences in action. Evolution and Human Behavior, 26, 227-244.

Little, A. C., Jones, B. C., Penton-Voak, I. S., Burt, D. M., \& Perrett, D. I. (2002). Partnership status and the temporal context of relationships influence human female preferences for sexual dimorphism in male face shape. Proceedings of the Royal Society of London Series B: Biological Sciences, 269, 1095-1100.

Magnusson, P. K. E., Rasmussen, F., \& Gyllensten, U. B. (2006). Height at age 18 years is a strong predictor of attained education later in life: Cohort study of over 950 000 Swedish men. International Journal of Epidemiology, 35, 658-663.

McCann, S. J. H. (2001). Height, societal threat, and the victory margin in presidential elections (1824-1992). Psychological Reports, 88, 741-742.

McManus, I. C., \& Mascie-Taylor, C. G. N. (1984). Human assortative mating for height - Non-linearity and heteroscedasticity. Human Biology, 56, 617-623.

Melamed, T. (1992). Personality correlates of physical height. Personality and Individual Differences, 13, 1349-1350.

Meyer, H. E., \& Selmer, R. (1999). Income, educational level and body height. Annals of Human Biology, 26, 219-227.

Montepare, J. M. (1995). The impact of variations in height on young childrens impressions of men and women. Journal of Nonverbal Behavior, 19, 31-47.

Mueller, U., \& Mazur, A. (2001). Evidence of unconstrained directional selection for male tallness. Behavioral Ecology and Sociobiology, 50, 302-311.

Mueller, W. H. (1979). Fertility and physique in a malnourished population. Human Biology, 51, 153-166.

Mueser, K. T., Grau, B. W., Sussman, S., \& Rosen, A. J. (1984). You're only as pretty as you feel - Facial expression as a determinant of physical attractiveness. Journal of Personality and Social Psychology, 46, 469-478.

Murray, G. R., \& Schmitz, J. D. (2011). Caveman politics: Evolutionary leadership preferences and physical stature. Social Science Quarterly, 92, 1215-1235.

Nettle, D. (2002). Women's height, reproductive success and the evolution of sexual dimorphism in modern humans. Proceedings of the Royal Society of London Series B: Biological Sciences, 269, 1919-1923.

Pawlowski, B. (2003). Variable preferences for sexual dimorphism in height as a strategy for increasing the pool of potential partners in humans. Proceedings of the Royal Society of London Series B: Biological Sciences, 270, 709-712.

Pawlowski, B., Dunbar, R. I. M., \& Lipowicz, A. (2000). Evolutionary fitness - Tall men have more reproductive success. Nature, 403, 156.

Pawlowski, B., \& Jasienska, G. (2005). Women's preferences for sexual dimorphism in height depend on menstrual cycle phase and expected duration of relationship. Biological Psychology, 70, 38-43.

Pawlowski, B., \& Koziel, S. (2002). The impact of traits offered in personal advertisements on response rates. Evolution and Human Behavior, 23, 139-149.

Pelin, C., Zagyapan, R., Yazici, C., \& Kurkcuoglu, A. (2010). Body height estimation from head and face dimensions: A different method. Journal of Forensic Sciences, $55,1326-1330$.

Perrett, D. I. (2010). In your face. The new science of human attraction. London, UK: Palgrave Macmillan.

Perrett, D. I., Lee, K. J., Penton-Voak, I., Rowland, D., Yoshikawa, S., Burt, D. M., et al. (1998). Effects of sexual dimorphism on facial attractiveness. Nature, 394, 884-887.

Peters, M., Rhodes, G., \& Simmons, L. W. (2007). Contributions of the face and body to overall attractiveness. Animal Behaviour, 73, 937-942.

Ramanathan, N., \& Chellappa, R. (2006). Face verification across age progression. IEEE Transactions on Image Processing, 15, 3349-3361.

Rao, P. P., Sowmya, J., Yoganarasimha, K., Menezes, R. G., Kanchan, T., \& Aswinidutt, R. (2009). Estimation of stature from cranial sutures in a South Indian male population. International Journal of Legal Medicine, 123, 271-276.

Rashad, I. (2008). Height, health, and income in the US, 1984-2005. Economics $\mathcal{E}$ Human Biology, 6, 108-126.

Re, D. E., Coetzee, V., Xiao, D. K., Buls, D., Tiddeman, B. P., Boothroyd, L. G., et al. (2011). Viewing heavy bodies enhances preferences for facial adiposity. Journal of Evolutionary Psychology, 9, 295-308. 
Rhodes, G. (2006). The evolutionary psychology of facial beauty. Annual Review of Psychology, 57, 199-226.

Rowland, D. A., \& Perrett, D. I. (1995). Manipulating facial appearance through shape and color. IEEE Computer Graphics and Applications, 15, 70-76.

Salska, I., Frederick, D. A. Pawlowski, B., Reilly, A. H., Laird, K. T., \& Rudd, N. A. (2008). Conditional mate preferences: Factors influencing preferences for height. Personality and Individual Differences, 44, 203-215.

Sear, R. (2010). Height and reproductive success. In U. J. Frey, C. Störmer, \& K. P. Willführ (Eds.). Homo Novus - A human without illusions (pp. 127-143). Berlin, Heidelberg: Springer.

Shepperd, J. A., \& Strathman, A. J. (1989). Attractiveness and height - The role of stature in dating preference, frequency of dating, and perceptions of attractiveness. Personality and Social Psychology Bulletin, 15, 617-627.

Sorokowski, P. (2010). Politicians' estimated height as an indicator of their popularity. European Journal of Social Psychology, 40, 1302-1309.

Steckel, R. H. (1983). Height and per capita income. Historical Methods, 16, 1-7.

Stulp, G., Pollet, T. V., Verhulst, S., \& Buunk, A. P. (2012). A curvilinear effect of height on reproductive success in human males. Behavioral Ecology and Sociobiology, $66,375-384$.

Swami, V., Furnham, A., Balakumar, N., Williams, C., Canaway, K., \& Stanistreet, D. (2008). Factors influencing preferences for height: A replication and extension. Personality and Individual Differences, 45, 395-400.
Thomsen, L., Frankenhuis, W. E., Ingold-Smith, M., \& Carey, S. (2011). Big and mighty: Preverbal infants mentally represent social dominance. Science, 331, 477-480.

Thornhill, R., \& Gangestad, S. W. (1999). Facial attractiveness. Trends in Cognitive Sciences, 3, 452-460.

Thornhill, R., \& Grammer, K. (1999). The body and face of woman: One ornament that signals quality? Evolution and Human Behavior, 20, 105-120.

Tiddeman, B., Burt, M., \& Perrett, D. (2001). Prototyping and transforming facial textures for perception research. IEEE Computer Graphics and Applications, 21, 42-50.

Vetta, A. (1975). Fertility, physique, and intensity of selection. Human Biology, 47, 283-293.

Windhager, S., Schaefer, K., \& Fink, B. (2011). Geometric morphometrics of male facial shape in relation to physical strength and perceived attractiveness, dominance, and masculinity. American Journal of Human Biology, 23, 805-814

\section{Web reference}

US National Library of Medicine (2012). Dwarfism. Retrieved from http:// www.nlm.nih.gov/medlineplus/dwarfism.html. 